\title{
Highly Sensitive High Performance Liquid Chromatography-Laser Induced Fluorescence for Proteomics Applications
}

\author{
Ajeetkumar Patil,, ${ }^{1}$ K. S. Choudhari, ${ }^{1}$ Vijendra Prabhu, ${ }^{1}$ V. K. Unnikrishnan, ${ }^{1}$ Sujatha Bhat, ${ }^{2}$ \\ Keerthilatha M. Pai, ${ }^{3}$ V. B. Kartha, ${ }^{4}$ and C. Santhosh ${ }^{1}$ \\ ${ }^{1}$ Centre for Atomic and Molecular Physics, Manipal University, Manipal 567104, India \\ ${ }^{2}$ Department of Microbiology, KMC International Center, Manipal 567104, India \\ ${ }^{3}$ Department of Oral Medicine and Radiology, Manipal College of Dental Sciences, Manipal 567104, India \\ ${ }^{4}$ Udayagiri, Deonar, Sion, Mumbai 400 088, India
}

Correspondence should be addressed to C. Santhosh, santhosh.cls@manipal.edu

Received 9 May 2012; Accepted 27 June 2012

Academic Editors: A. A. Ensafi, A. Huczynski, and B. Liu

Copyright (C) 2012 Ajeetkumar Patil et al. This is an open access article distributed under the Creative Commons Attribution License, which permits unrestricted use, distribution, and reproduction in any medium, provided the original work is properly cited.

This paper describes the sensitivity study and performance evaluation of high-performance liquid chromatography-laser-induced fluorescence detection (HPLC-LIF) system assembled in our laboratory for proteomics applications. The limits of Detection (LOD) of several serum proteins have been estimated with this instrument and are found to be much lower compared to other commonly used proteomics techniques like SELDI, MALDI, 2-D-SDS-PAGE, and so forth. Techniques for improving the LOD still further with similar setup are briefly discussed. Using the system, protein profiles of serum in normal, malignant, and premalignant conditions were recorded for different malignancy situations.

\section{Introduction}

High-performance liquid chromatography (HPLC) is a versatile tool for the separation and analysis of biological and pharmaceutical compounds. The analysis of many trace analytes even in complex systems can be carried out with the effective utilization of HPLC and proper selection of a highly sensitive detection technique. Currently, various detection techniques are in use with HPLC, namely, UV-visible absorption, fluorescence, refractive index, nuclear magnetic resonance (NMR), mass spectrometry (MS), pulsed electrochemical detection (PED), and so forth [1-3]. Laser-induced fluorescence (LIF) is one of the most sensitive techniques for qualitative and quantitative analysis [4-13]. Improving the detection limit of HPLC still further is one of the main challenges in analytical chemistry. The usual methods for this are (i) increasing the amount of analyte either by injection of larger volumes of sample or by analyte preconcentration and (ii) improving the signal-to-noise ratio $(\mathrm{S} / \mathrm{N})$ through instrument optimization [11]. Extensive research and development made for improving the sensitivity/detection limits have led to various new methodologies and significant modifications in the detection schemes. Derivatization is a widely used technique, where efficient fluorescent molecules are mixed or tagged with the sample which in turn helps to detect and identify the analyte with higher sensitivity. Since the number of standard fluorescent molecules available for this application is small, the derivatization methods have got limited popularity. Even though this method has achieved detection limits for amino acids at subfemtomole levels [12], the existing methods have several drawbacks like derivative instability, reagent interferences, long preparation time, and so forth [2].

There is an urgent need for determination of extremely small quantities of proteins in physiological samples, for investigations in areas like "single-cell omics," CTC- Circulating tumor cells, and so forth, where the protein profiles in picoliter amounts of samples have to be detected even when 
they are present at extremely low levels. This necessitates detection limits of the order of subfemtomoles since the concentrations of many single proteins in the 10-20 picoliter single-cell sample will be in the millimicromolar range. In order to enhance detection sensitivity to values much better than those usually available in commercial systems, we incorporated laser-induced fluorescence (LIF) as the detection technique in our HPLC system [5]. Our initial studies established the usefulness of HPLC LIF for highsensitivity detection of trace components in complex mixtures of proteins [6-9]. The exceptional properties of laser as an excitation source have improved the detection limits of HPLC by several orders. In addition to known advantages of laser, the accurate focusing of the excitation source onto the microbore capillary flow cell, designed and fabricated in our lab, allowed excitation of picoliter amounts of sample without loss of excitation energy [7-9]. This, combined with the elimination of scattered laser background by the use of dielectric laser mirrors [10] and a double monochromator, enabled us to improve the limit of detection to more than 100 times than that of the conventional HPLC systems [9].

The limit of detection (LOD) is defined as the smallest concentration/amount of analyte that can be detected with reasonable certainty by a given analytical procedure [14]. The peak-to-peak noise was measured over a sufficiently wide region of chromatogram, containing the analyte peak and at least 20 times the width of the analyte peak. The LOD was calculated by taking the quotient of an arbitrary detector signal and the sensitivity, where sensitivity is defined as the slope of the calibration curve-signal output per unit concentration or amount of analyte introduced [11]. Since our system was for proteomics application, we have selected some major serum proteins for LOD determination. Serum contains $60-80 \mathrm{mg}$ of protein $/ \mathrm{mL}$ in addition to various small molecules including salts, amino acids, sugars, and lipids [15]. More than 10,000 unique proteins are known to be present in human serum $[16,17]$. Albumin, immunoglobulins, transferrin, haptoglobin, and lipoproteins are the major protein constituents of serum which contribute with $99 \%$ of protein mass of serum [15, $18,19]$. Creatine phosphokinase (CPK), a key enzyme in cells, is widely used as a biomarker for myocardial infarction $[20,21]$. Insulin is one of the peptide hormones made up of 51 amino acids, and its role in different types of diabetes is well known [22]. Varying levels of this hormone are used as risk factor to monitor cardiovascular diseases [23-25]. The protein ferritin is considered as store house of iron, and transferrin plays a key role in transporting it. Serum chromatograms were recorded using the HPLC-LIF system, and the limits of detection were calculated for some of the above major serum proteins.

\section{Materials and Methods}

HPLC grade solvents (water, acetonitrile (ACN), methanol, and isopropanol) in experiment were procured from Merck (Germany). Standard serum proteins (HSA, transferrin, CPK, ferritin, and insulin) were obtained from SigmaAldrich (USA).
2.1. Sample Preparation. HSA (concentrations 2 pmol, $1 \mathrm{pmol}, 500 \mathrm{fmol}, 250 \mathrm{fmol}$, and $125 \mathrm{fmol})$, transferrin (500 to $62.5 \mathrm{fmol}$ ), CPK (1600 to $200 \mathrm{fmol}$ ), ferritin (4800 to $600 \mathrm{fmol}$ ), and insulin (4250 to $531.2 \mathrm{fmol}$ ) solutions were prepared by dissolving the required amounts of individual proteins in HPLC grade water.

Blood samples from 14 healthy volunteers and pathologically/clinically certified 15 premalignant and 13 malignant cases were collected from Manipal College of Dental Sciences, Manipal, with informed consent of volunteers. Ethical Clearance from the Manipal University Ethical Committee was obtained for this study. A freshly collected blood sample was allowed to stand undisturbed for 30 minutes for coagulation. Thereafter, the sample is subjected to centrifugation twice at $5000 \mathrm{rpm}$ (699 g-force) (Costar minicentrifuge, 10 MVSS, USA). The supernatant serum is collected and used after dilution to the required level (up to $1: 3000$ ) with HPLC grade water.

2.2. Experimental Setup. The experimental setup includes two main parts, the HPLC unit for the protein separation and laser-induced fluorescence (LIF) system for detection of the separated proteins. Details are discussed in the following sections.

2.2.1. Protein Separation Part. The HPLC-LIF setup (Figure 1) consists of an HP 1100 series high-performance liquid chromatography system with a G1322A degasser, G1311A pump, and a manual injector (model no. 7725i, Rheodyne) coupled to a Vydac 219TP52 reversed-phase narrow bore column $(2.1 \mathrm{~mm}$ inner diameter, $250 \mathrm{~mm}$ in length, GRACE Vydac, USA) packed with $5 \mu \mathrm{m}$ biphenyl particles of pore size $300 \AA$. The effluent from the column was sent into a rigidly fixed capillary flow cell fabricated in our laboratory. The flow cell is made of UV grade quartz capillary $(75 \mu \mathrm{m}$ inner diameter and $360 \mu \mathrm{m}$ outer diameter, FS-175 Upchurch Scientific, USA). The capillary is connected to PEEK tubing (part no. 5042-6462, $1.58 \mathrm{~mm}$ outer diameter, $175 \mu \mathrm{m}$ inner diameter, Agilent) using fingertight fittings (part no. 5063-6591, Agilent), zero dead volume union (Part no: Agilent 0100-0900), and appropriate sleeves (Upchurch Scientific, F-388X). Flow cell is accurately mounted on precession mounts for reproducible excitation and collection of fluorescence over periods of several months.

2.2.2. Protein Fluorescence Detection. For the protein detection, we used laser-induced fluorescence. The efficient excitation of proteins was achieved by illuminating with $257 \mathrm{~nm}$ laser emission $(10 \mathrm{~mW})$ from a continuous wave, frequency-doubled $\mathrm{Ar}^{+}$laser (Innova 90C FreD, Coherent, $514.5 \mathrm{~nm}$ laser line), focused onto the capillary cell. The laser beam was chopped continuously with an EG\&G Model 651 optical chopper at $20 \mathrm{~Hz}$, giving a reference for the lock-in detection. The emitted fluorescence from the proteins was collected using suitable optics that focused the radiation on to the entrance slit of the monochromator (Jobin Yvon DH10 SPEX), set at $340 \mathrm{~nm}$. The slit width of the monochromator (with 600 grooves $/ \mathrm{mm}$ grating) was fixed at $1.7 \mathrm{~mm}$ which 


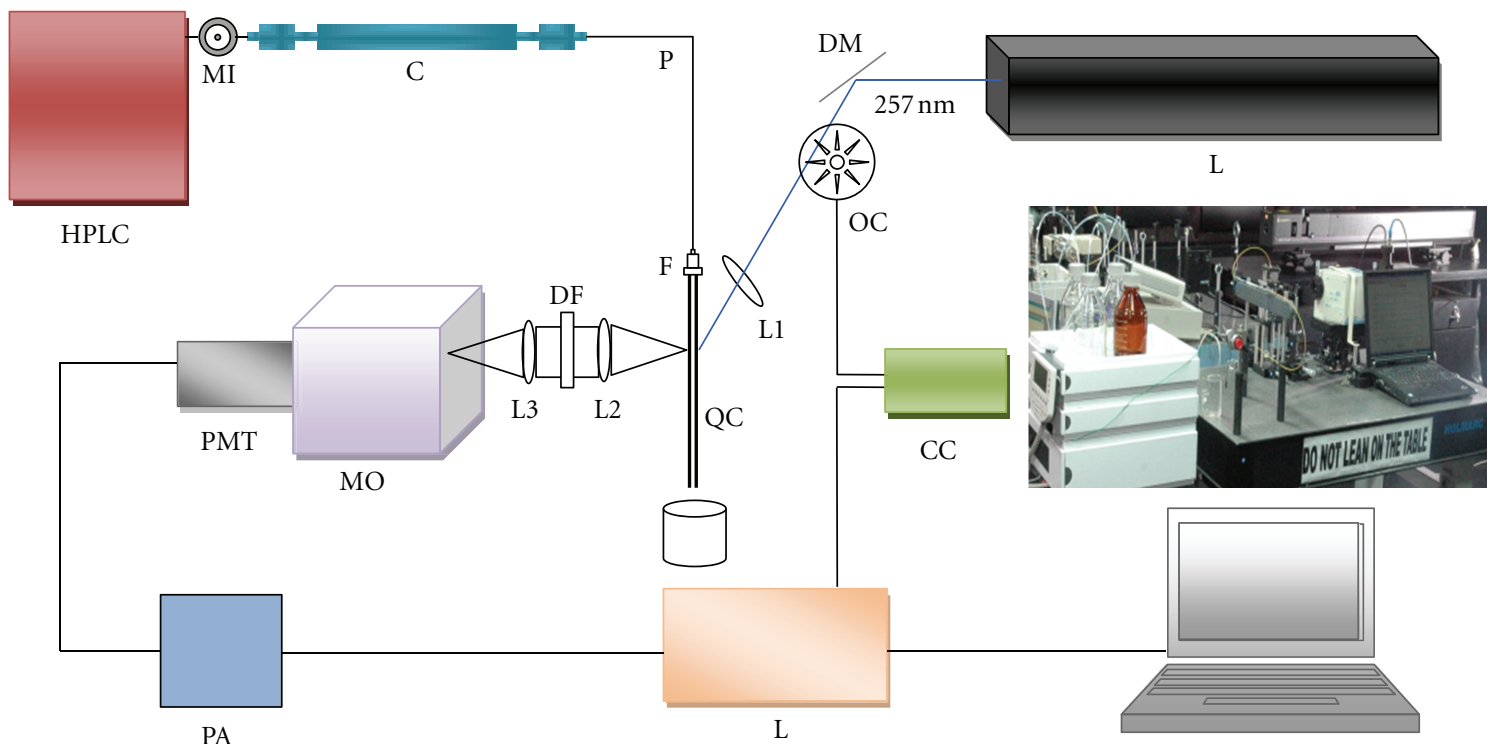

$\begin{array}{llll}\text { L: } & \mathrm{Ar}^{+} \text {laser }(257 \mathrm{~nm}) & \text { FT: } & \text { Finger tight fittings } \\ \text { DM: } & \text { Dichroic mirror } & \text { DF: } & \text { Dichroic filter } \\ \text { OC: } & \text { Optical chopper } & \text { MO: } & \text { Monochromator } \\ \text { CC: } & \text { Chopper controller } & \text { QC: } & \text { Quartz capillary } \\ \text { CL: } & \text { Chromatographic column } & \text { L1, L2, L3: Lenses } \\ \text { PMT: } & \text { Photomultiplier tube } & \text { PA: } & \text { Preamplifier } \\ \text { HPLC: } & \text { High-performance liquid chromatography system } & \text { LA: } & \text { Lock-in amplier } \\ \text { PT: } & \text { PEEK tubing } & \text { MI: } & \text { Manual injector }\end{array}$

FIGURE 1: Block diagram of high-performance liquid chromatography-(HPLC-) laser-induced fluorescence (LIF) setup.

gave a spectral bandpass of $\sim 14 \mathrm{~nm}$. The fluorescence was detected by a photomultiplier tube (Hamamatsu R750) operated at $-950 \mathrm{~V}$, coupled through a preamplifier (EG\&G Model 5113), and operated at gain 25, which is connected to a lock-in amplifier (EG\&G Model 7265). The output of the lock-in amplifier was interfaced with a computer to record the chromatograms.

Diluted samples solutions were injected into the HPLC system and fitted with a $20 \mu \mathrm{L}$ sample loop (7755-022) (Rheodyne, USA). For all the runs, mobile-phase A consisted of water and $0.1 \%$ TFA, and mobile-phase B, acetonitrile with $0.1 \%$ TFA. Proteins were eluted under the gradient runs with A: $70-40 \%$, B: $30-60 \%$ in 0-60 minutes, followed by B: $60-100 \%$ in 1 minute. The $100 \%$ ACN run was continued for another 14 minutes taking the total run time to 75 minutes. After each run, column was regenerated with water solvent for 15 minutes with a constant flow rate $0.2 \mathrm{~mL} / \mathrm{min}$. Blank was recorded after each run to ensure that the column was clean prior to every sample run. Under the same conditions, each chromatograms (protein profiles) belonging to normal, premalignant, and malignant samples were recorded. All data processing involving baseline correction, background subtraction, normalization, and calibration to a uniform scale was done using PLS Plus IQ (Galactic Corporation, USA).

\section{Results and Discussion}

The main objective of the present work was to explore how much the sensitivity of the HPLC-LIF system can be increased, for marker protein detection and recording of protein profiles of body fluids, to demonstrate its use in routine clinical applications. It is very well known that many biochemical changes precede and continue to take place in the progression from normal state to premalignancy (initial stages) and malignancy [26]. To detect the changes in the early stages, one should thus have very high sensitivity. For example, even at millimolar concentrations, a single cell (few picoliters) can give only femtomoles of any species, and one should be able to detect the presence of a few malignant cells (or equivalent molecular species) in the presence of a millionfold higher level of normal species. HPLC-LIF technique can be one of the promising techniques for such application. Earlier studies [27] have tried fluorescence of whole serum for discrimination of normal and malignant samples in breast cancer. This may enable some amount of discrimination, but one cannot expect it to be useful for routine applications, since fluorescence from most proteins fall in the same spectral range, and major components like HSA may completely mask any fluorescence from tumor markers, which may be present only in trace quantities. 


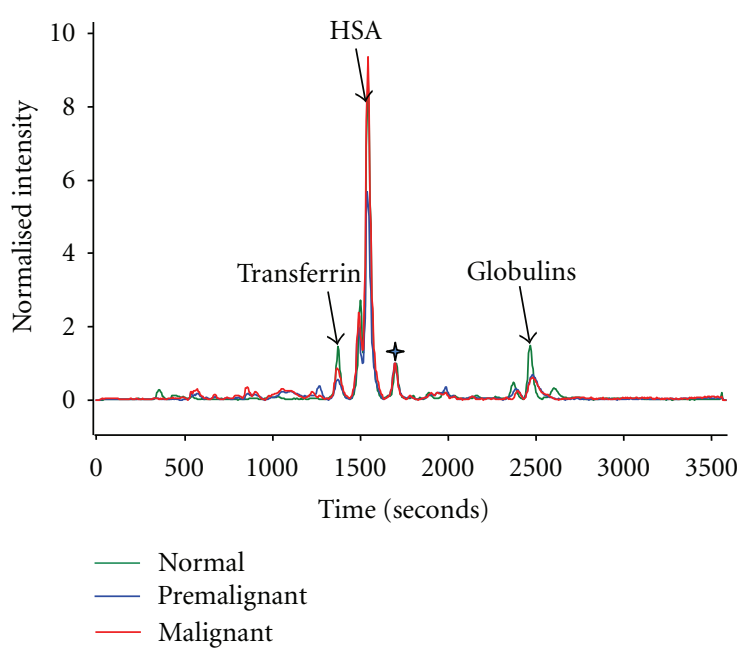

(a)

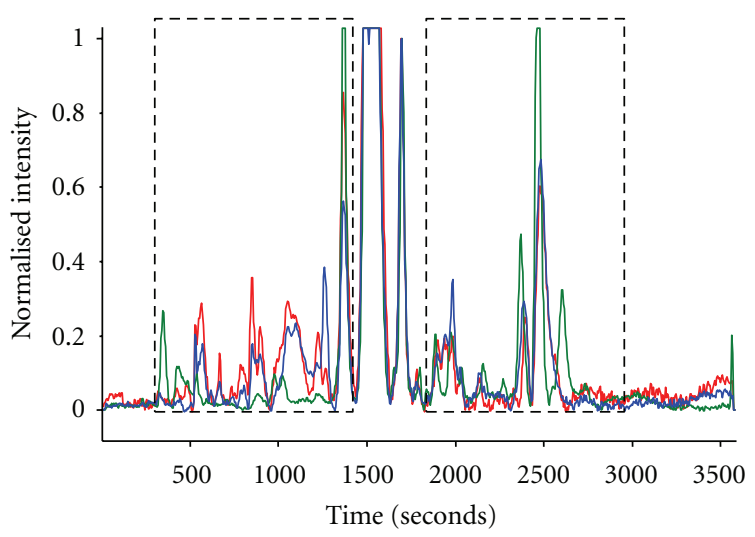

(b)

Figure 2: (a) Serum protein profiles of normal, premalignant, and oral malignant conditions. (b) Protein profiles enlarged by a scale of 10 to show the minor proteins.

TABLE 1: Comparison of detection limits of 3 serum proteins with the current HPLC-LIF system and available data from literature.

\begin{tabular}{lccc}
\hline Sl. No. & Proteins & Literature Limit of Detection & Current HPLC-LIF Limit of Detection \\
\hline 1 & Creatine Phosphokinase (CPK) & $8 \mathrm{U} / \mathrm{L}^{33}$ & $7.3(0.05) \mathrm{fmoles}$ \\
2 & Ferritin & $0.25 \mathrm{ng} / \mathrm{mL}^{30}(\approx 52.1$ picomoles $)$ & $76(0.1) \mathrm{fmoles}$ \\
3 & Human Serum Albumin (HSA) & $17.32 \mathrm{ng} / \mathrm{mL}^{34}(\approx 0.26$ nmoles $)$ & $11.6(0.01) \mathrm{fmoles}$ \\
4 & Transferrin & $50 \mathrm{pg} / \mathrm{mL}^{31}(\approx 0.625$ nmoles $)$ & $2.1(0.001) \mathrm{fmoles}$ \\
5 & Insulin & $2 \mathrm{ppm}^{28}, 30 \mathrm{ppm}^{29}$ & $17.4(0.01) \mathrm{fmoles}$ \\
\hline
\end{tabular}

Using the present setup, the separation of the individual proteins combined with fluorescence detection from each enables one to detect even very small changes in protein composition leading to possible early detection of any changes in biomolecular composition and hence onset of disease. This is clearly illustrated in Figure 2. Figure 2(a) shows typical protein profiles with 20 microliters of 500 times diluted serum from healthy, premalignant, and malignant subjects. Figure 2(a) shows the same profiles after enlarging the intensity scale 10 -fold. Normal samples were taken from volunteers (no tobacco habits, not under any treatment or drug administration, no menstrual period, but pregnancy allowed, and no disease symptoms) in age group of 20-43 years. From the signal-to-noise ratio in Figure 2(b), it is clear that even the very weak peaks can be expanded another 1050 times to observe still lower concentrations of any new proteins involved in disease conditions.

Though the protein profile of serum samples with varying relative intensities provides patterns sufficient for the discrimination of normal and disease conditions, sometimes the actual concentration of the constituent proteins may have to be estimated. For example, quantifying the insulin concentration in blood serum could be useful for the study of type 1 and type 2 diabetes. These quantitative estimations can be done by identifying the required proteins individually and generating calibration curves for each one of them. Figure 3 shows the overlaid chromatograms corresponding to different concentrations of selected proteins along with a typical blank. Blank chromatogram was recorded in all cases, before recording sample chromatogram to make sure that there is no interference due to any residual proteins in the column.

Figure 4 shows the calibration plots for the standard proteins under study. As usual, calibration curves were drawn by plotting peak intensity against concentration. The LODs for ferritin, insulin, human serum albumin, creatin phosphokinase, and transferrin were calculated and are found to be 76 (0.1) fmoles, 17.4 (0.01) fmoles, 11.6 (0.01) fmoles, 7.3 (0.05) fmoles, and 2.1 (0.001) fmoles, respectively. We compared the sensitivity of the current system with the sensitivities of other protein detection techniques (Table 1) which shows that the HPLC-LIF techniques described here have got higher sensitivity than those reported by other techniques.

We estimated the CPK level in the serum sample collected from a clinically premalignant oral submucous Fibrosis (OSMF) case. Figure 5 shows the serum chromatogram of the OSMF sample. The estimated concentration from the calibration curve, for the CPK in the blood sample of the OSMF sample, is $\sim 2$ pmoles. Detection limit for insulin is found to be 2 pmoles by amperometric method using renewable nickel powder-doped carbon composite electrode [28]. By enzyme-linked sandwich immunoassay using laser-induced fluorimetric method, the detected quantity of insulin was 



FIgURE 3: (a) Chromatograms of standard proteins at 4 different concentrations: (a) blank, (b) creatine phosphokinase (CPK), (c) ferritin, (d) human serum albumin (HSA), (e) transferrin, and (f) insulin.

30 pmole [29]. Minimum amount of detectable serum ferritin is $0.04 \mu \mathrm{g}$ using rapid counterimmunoelectrophoresis technique [30]. LOD for serum ferritin is reported to be $0.25 \mathrm{ng} / \mathrm{mL}$ using MAP- $\mathrm{H}_{2} \mathrm{O}_{2}-\mathrm{HRP}$ volumetric enzymelinked immunoassay [31]. Transferrin was detected at $50 \mathrm{pg} / \mathrm{mL}$ level using a novel capacitive immunosensor based on ultra-thin alumina sol-gel-derived films and gold nanoparticles [32]. Human serum albumin was detected at picomole levels using sensitive photo-induced fluorogenic reaction [33]. Xu et al. reported the HSA detection limit of $17.35 \mathrm{ng} / \mathrm{mL}(\approx 0.26$ nmoles $)$ using chemiluminescence method [34]. The biomarker for myocardial infarction, creatine kinase, was detected at $8 \mathrm{U} / \mathrm{L}$ using off-line and on-line modes with capillary electrophoresis [35]. We have 


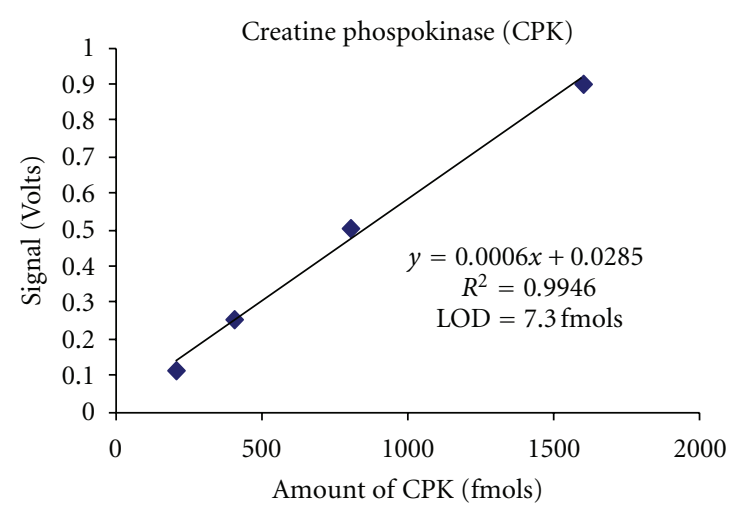

(a)



(c)

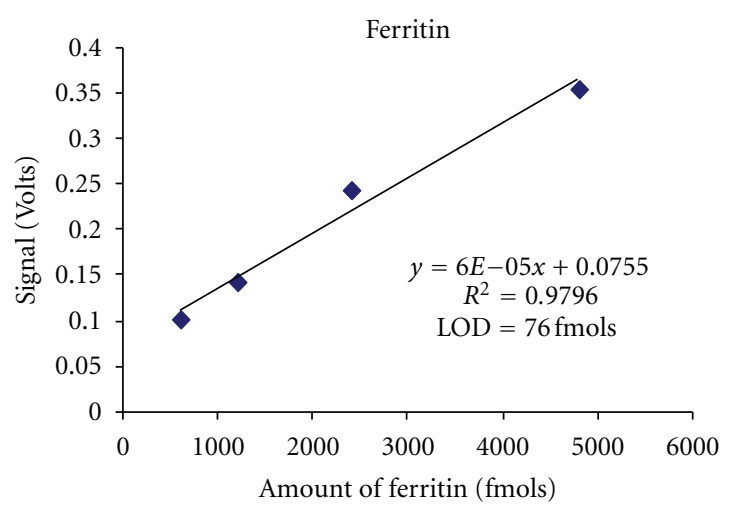

(b)



(d)



(e)

FIgURE 4: Calibration curves of standard proteins (after baseline correction): (a) CPK, (b) Ferritin, (c) HAS, (d) Transferrin, and (e) Insulin.

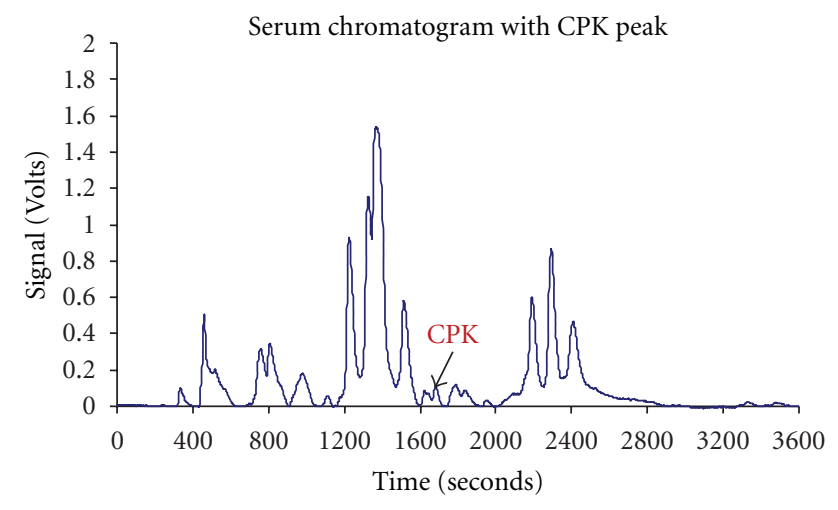

FIGURE 5: Serum chromatogram from an oral submucous fibrosis (OSMF) case showing CPK peak. observed similar sensitivities for markers like CEA and RBP (riboflavin-binding protein) with our system [36]. In view of the extremely good detection level of the serum proteins by HPLC-LIF system with respect to the above-mentioned literature data (Table 1), it can be seen that HPLC-LIF can be a reliable, faster, and very sensitive technique for the determination of marker proteins in body fluids. The recording time of the protein profile of a sample using the biphenyl revered-phase column will take 60 minutes, and this can be made faster using faster columns available for protein separations.

The sensitivity can be further improved to subfemtomoles with some modifications in the system. There are several ways to improve the detection limit in the present setup. Sensitivity can be increased further by increasing the 


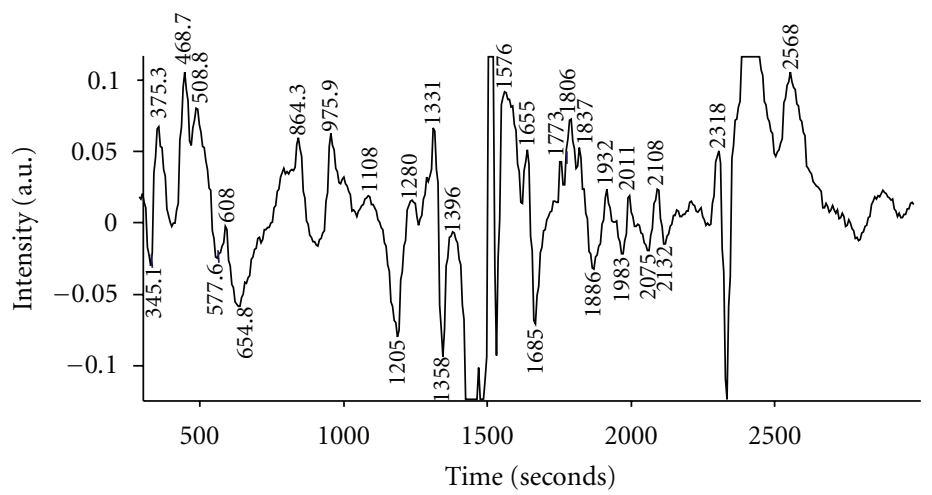

(a)



(b)

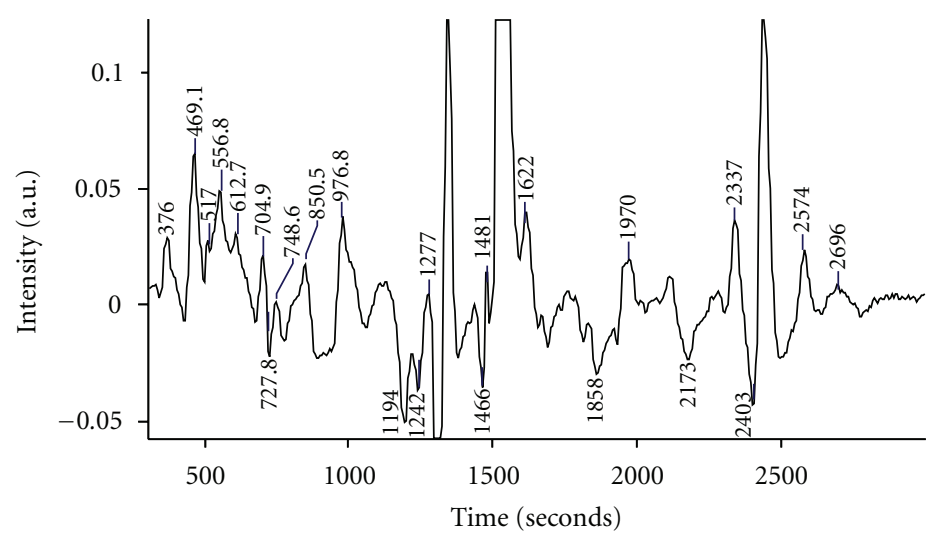

(c)

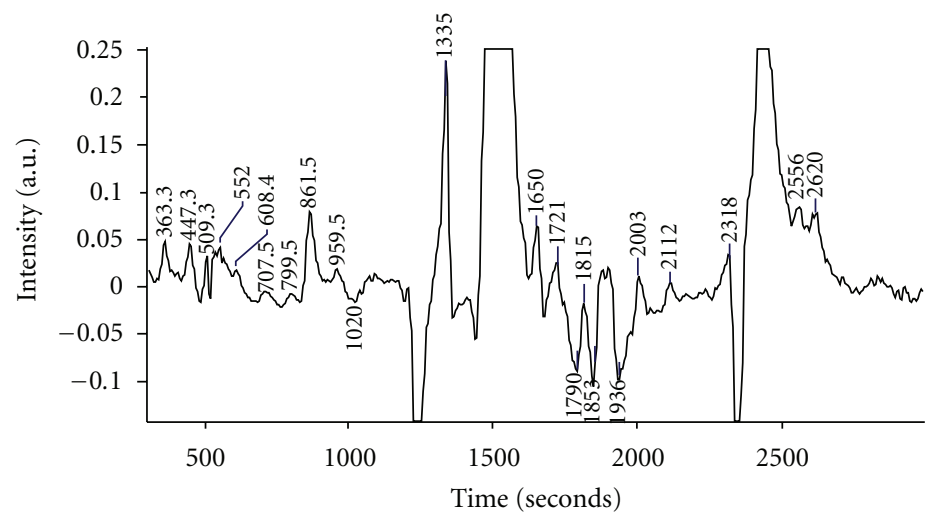

(d)

FIGURE 6: Difference protein profile of the serum: (a) mean of normal mean of stage I, (b) mean of normal mean of stage II, (c) mean of normal mean of stage III, and (d) Mean of normal-mean of stage IV. 
fluorescence collection by using high numerical aperture lenses or microscope objectives (N.A. $=1$ or more) $[10,37]$ instead of using present $\mathrm{f} / 1$ lens (N.A.0.5) for fluorescence collection, increase in the illumination of the sample volume by using suitable optics, for example, by changing the current $5 \mathrm{~cm}$ focal length to lenses with longer focal lengths or multipassing the laser, increasing the amount of total fluorescence seen by the detection system by replacing the monochromator with bandpass filters, and so forth. Higher PMT voltage, gain of lock-in amplifier, laser power, and better signal processing techniques [10,38] all can employ further increase in sensitivity.

Though the calibration curves above have been prepared by injecting individual proteins in the system, from Figure 2 it can be seen that each different protein present in the sample can be detected and quantified individually, whereas most of the other methods mentioned above can detect only one protein at a time. This has two major advantages: ability to see as many markers as required in a single run which reduces the cost of the diagnostic process; much more important, diagnostic conclusions based on multiple markers are much more robust compared to evaluations which depend only on one marker [39]. A highly sensitive HPLC-LIF technique with subfemtomole detection capability can provide a highly reliable protein profile, where the presence of even very small amounts of new/altered proteins (compared to normal condition) can be seen accurately. The technique is thus eminently suitable for early diagnosis, staging, and followup in therapy for various diseases like diabetes, myocardial infarction, and cancer which remain clinically silent over long periods [9:10;40:42].

To illustrate the validity of the above considerations, in Figure 6, we show the differences in protein profiles of serum of subjects in different stages of cervical cancer, compared to serum from normal subjects. The advantages of the very high sensitivity of our HPLC-LIF setup can be seen from this figure, which highlights even minor differences in protein profile in different stages of the disease. It is clear from Figure 6 that protein profiles in different stages of cervical cancer differ very much, not only from that of normal serum, but also between themselves. The differences arise from changes in relative concentrations of some of the proteins present in normal conditions, and from formation of new proteins. The major problem in using tumor markers for staging and early detection is the difficulty in defining the ranges for the relevant situations. Many markers are known to be present in small amounts even under normal conditions, and many others are produced in enhanced amounts under conditions other than malignancy [40]. It will be thus very difficult to depend only on a single marker for early detection or staging. A pattern analysis of the total profile can circumvent this difficulty, since, as seen from Figure 6, with the high-sensitivity HPLC-LIF system we can combine the observation of systematic changes from stage to stage, with characteristic unique peaks to make unambiguous diagnosis. We have used principal-component analysis-(PCA-) and artificial neural network-(ANN-) based pattern analyses techniques with our protein profiles to discriminate between different stages of cervical malignancy
[41] between normal, malignant, and benign conditions in breast and ovarian malignancies [9:10, $40: 42]$ and normal, premalignant, and malignant conditions in oral cancer [42].

\section{Conclusions}

Detection limits of human serum albumin, transferrin, ferritin, insulin and creatine phosphokinase (CPK) in serum by the HPLC-LIF system, assembled in our laboratory, have been determined and are found to be $76 \mathrm{fmol}, 17.4 \mathrm{fmol}$, $11.6 \mathrm{fmol}, 7.3 \mathrm{fmol}$, and $2.1 \mathrm{fmol}$, respectively. These limits are better than those achieved by other currently available techniques. Subfemtomole to attomole sensitivity can be easily achieved by incorporating minor modifications in the detection part of the system. The results from our system have shown that pattern analysis of high-sensitivity HPLCLIF protein profiles enables unambiguous classification of normal, premalignant, benign, and malignant conditions in various malignancies.

\section{Conflict of Interests}

The authors declare that they have no conflict of interests.

\section{Acknowledgment}

Part of the work was done under the project "Study of the Protein Profile of the Clinical Samples for the Early Diagnosis of Female Cancers," Department of Science and Technology, Government of India (Project no. SR/S2/LOP/05/2003).

\section{References}

[1] W. W. Christie, "Detectors for high-performance liquid chromatography of lipids with special reference to evaporative light scattering detection," Advances in Lipid Methodology, pp. 239-271, 1992.

[2] K. Petritis, C. Elfakir, and M. Dreux, "A comparative study of commercial liquid chromatographic detectors for the analysis of underivatized amino acids," Journal of Chromatography A, vol. 961, no. 1, pp. 9-21, 2002.

[3] G. D. Reed, "An evaluation of electrochemical detection in reverse-phase HPLC," Journal of High Resolution Chromatography \& Chromatography Communications, vol. 11, pp. 675677, 1988.

[4] S. A. Soper, S. M. Lunte, and T. Kuwana, "High sensitivity fluorescence detection of naphthalenedialdehyde derivatized amino acids with a low power helium-cadmium laser for high performance liquid chromatographic analysis," Analytical Sciences, vol. 5, pp. 23-29, 1989.

[5] V. B. Kartha, S. S. Nayak, J. Kurien, J. Jacob, and M. Valiathan, "Investigation of laser spectroscopy methods for early diagnosis of neoplasia: development of instrumentation and analytical techniques," DST No SP/S2/L01/98, Department of Science and Technology, Government of India, 1998.

[6] K. Venkatakrishna, K. M. Pai, C. M. Krishna et al., "Protein profiles in oral pre-malignancies: a laser spectroscopy study," in Proceedings of the 4th DAE-BRNS National Laser Symposium, vol. 345, Allied Publishers, New Delhi, India, 2001. 
[7] K. Venkatakrishna, V. B. Kartha, K. M. Pai et al., "HPLC-LIF for early detection of oral cancer," Current Science, vol. 84, no. 4, pp. 551-557, 2003.

[8] S. K. Singh, R. L. Martis, Sujatha et al., "Protein profile study of clinical samples of ovarian cancer using High Performance Liquid Chromatography-Laser Induced Fluorescence (HPLCLIF)," in Proceedings of the Ultrasensitive and Single-Molecule Detection Technologies, San Jose, Calif, USA, January 2006.

[9] Sujatha, L. Rai, B. R. Krishnanand, K. K. Mahato, V. B. Kartha, and C. Santhosh, "Protein profile study of the cervical cancer using HPLC- LIF," in Proceedings of the Ultrasensitive and Single-Molecule Detection Technologies, San Jose, Calif, USA, January 2006.

[10] Sujatha, Protein profile and laser fluorescence spectroscopic studies of clinical samples for early detection of cervical cancer [Ph.D. thesis], Manipal University, 2009.

[11] E. S. Yeung and M. J. Sepaniak, "Laser fluorometric detection in liquid chromatography," Analytical Chemistry, vol. 52, no. 13, pp. 1465A-1471A, 1980.

[12] E. S. Yeung and R. E. Synovec, "Detectors for liquid chomatography," Analytical Chemistry, vol. 58, no. 12, 1986.

[13] K. C. Chan, T. D. Veenstra, and H. J. Issaq, "Comparison of fluorescence, laser-induced fluorescence, and ultraviolet absorbance detection for measuring HPLC fractionated protein/peptide mixtures," Analytical Chemistry, vol. 83, no. 6, pp. 2394-2396, 2011.

[14] M. J. Sepaniak, "The clinical use of laser-excited fluorometry," Clinical Chemistry, vol. 31, no. 5, pp. 671-678, 1985.

[15] C. A. Burtis and E. R. Ashwood, Tiets Fundamentals of Clinical Chemistry, W.B.Saunders Company, Philadelphia, Pa, USA, 5 edition, 2001.

[16] J. N. Adkins, S. M. Varnum, K. J. Auberry et al., "Toward a human blood serum proteome: analysis by multidimensional separation coupled with mass spectrometry," Molecular \& Cellular Proteomics, vol. 1, no. 12, pp. 947-955, 2002.

[17] C. Wrotnowski, "The future of plasma proteins," Genetic Engineering News, vol. 18, p. 14, 1998.

[18] M. W. Turner and B. Hulme, The Plasma Proteins: An Introduction, Pitman Medical \& Scientific Publishing, London, UK, 1970.

[19] N. L. Anderson and N. G. Anderson, "The human plasma proteome: history, character, and diagnostic prospects," Molecular \& Cellular Proteomics, vol. 1, no. 11, pp. 845-867, 2002.

[20] P. D. Griffiths, "Serum levels of creatine phosphokinase," Journal of Clinical Pathology, vol. 17, pp. 56-57, 1964.

[21] D. Neumeier, M. Knedel, U. Wurzburg, N. Hennrich, and H. Lang, "Immunologischer nachweis von creatinkinase-MB im serum beim myokardinfarkt," Klin Wochenschr, vol. 53, pp. 329-333, 1975.

[22] F. Sanger, "Chemistry of insulin," Science, vol. 129, no. 3359, pp. 1340-1344, 1959.

[23] K. Pyorala, "Relationship of glucose tolerance and plasma insulin to the incidence of coronary heart disease: results from two population studies in Finland," Diabetes Care, vol. 2, no. 2, pp. 131-141, 1979.

[24] P. Ducimetiere, E. Eschwege, and L. Papoz, "Relationship of plasma insulin levels to the incidence of myocardial infarction and coronary heart disease mortality in a middleaged population," Diabetologia, vol. 19, no. 3, pp. 205-210, 1980.

[25] T. A. Welborn and K. Wearne, "Coronary heart disease incidence and cardiovascular mortality in Busselton with reference to glucose and insulin concentrations," Diabetes Care, vol. 2, no. 2, pp. 154-160, 1979.
[26] B. Alberts, A. Johnson, J. Lewis, M. Raff, K. Roberts, and P. Walter, Molecular Biology of the Cell, Garland Science, New York, NY, USA, 4th edition, 2007.

[27] S. Menon, Sujatha, K. K. Kumar et al., "Protein profile study of breast cancer tissues using HPLC-LIF: a pilot study," in Proceedings of the Advanced Biomedical and Clinical Diagnostic Systems V (SPIE '07), San Jose, Calif, USA, January 2007.

[28] A. Salimi, M. Roushani, S. Soltanian, and R. Hallaj, "Picomolar detection of insulin at renewable nickel powder-doped carbon composite electrode," Analytical Chemistry, vol. 79, no. 19, pp. 7431-7438, 2007.

[29] S. D. Lidofsky, W. D. Hinsberg, and R. N. Zare, "Enzymelinked sandwich immunoassay for insulin using laser fluorimetric detection," Proceedings of the National Academy of Sciences of the United States of America, vol. 78, no. 3, pp. 19011905, 1981.

[30] M. R. Beamish, P. Llewellin, and A. Jacobs, "A rapid method for the detection of ferritin in serum," Journal of Clinical Pathology, vol. 24, no. 6, pp. 581-582, 1971.

[31] S. Zhang, K. Jiao, H. Chen, and M. Wang, "Detection of ferritin in human serum with a $\mathrm{MAP}-\mathrm{H}_{2} \mathrm{O}_{2}$ - $\mathrm{HRP}$ voltammetric enzyme-linked immunoassay system," Talanta, vol. 50, no. 1, pp. 95-101, 1999.

[32] T. Yin, W. Wei, L. Yang, X. Gao, and Y. Gao, "A novel capacitive immunosensor for transferrin detection based on ultrathin alumina sol-gel-derived films and gold nanoparticles," Sensors and Actuators B, vol. 117, no. 1, pp. 286-294, 2006.

[33] Q. Z. Zhu, Y. Y. Lin, D. H. Li, J. G. Xu, and X. Q. Guo, "Detection of human serum albumin by a photoinduced fluorogenic reaction," Analytical Letters, vol. 32, no. 9, pp. 1775-1786, 1999.

[34] W. Xu, Y. Wei, D. Xing, Q. Chen, and S. Luo, "Quantification of human serum albumin by highly sensitive chemiluminescence method," in Proceedings of the IEEE/ICME International Conference on Complex Medical Engineering (CME '07), pp. 1693-1697, May 2007.

[35] J. M. Fujima and N. D. Danielson, "Determination of creatine kinase activity and phosphocreatine in off-line and on-line modes with capillary electrophoresis," Analytica Chimica Acta, vol. 375, no. 3, pp. 233-241, 1998.

[36] M. S. Chidananda, Laser spectroscopic and biochemical investigations on clinical samples in cancer of human uterine cervix [Ph.D. thesis], Manipal University, 2007.

[37] D. T. Chiu, S. J. Lillard, R. H. Scheller et al., "Probing single secretory vesicles with capillary electrophoresis," Science, vol. 279, no. 5354, pp. 1190-1193, 1998.

[38] P. C. D. Hobbs, "Ultrasensitive laser measurements without tears," Applied Optics, vol. 36, no. 4, pp. 903-920, 1997.

[39] A. J. Rai and D. W. Chan, "Cancer proteomics: serum diagnostics for tumor marker discovery," Annals of the New York Academy of Sciences, vol. 1022, pp. 286-294, 2004.

[40] V. Kumar, R. S. Cotran, and S. L. Robbins, Basic Pathology, Prism Books, Bangalore, India, 5th edition, 1992.

[41] Sujatha, L. Rai, P. Kumar, K. K. Mahato, V. B. Kartha, and C. Santhosh, "Serum protein profile study of normal and cervical cancer subjects by high performance liquid chromatography with laser-induced fluorescence," Journal of Biomedical Optics, vol. 13, no. 5, Article ID 054062, 2009.

[42] A. Patil, V. Prabhu, K. S. Choudhari et al., "Evaluation of high-performance liquid chromatography laser-induced fluorescence for serum protein profiling for early diagnosis of oral cancer," Journal of Biomedical Optics, vol. 15, no. 6, Article ID 067007, 2010. 


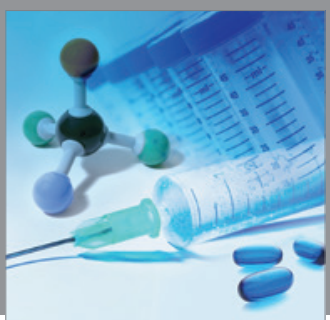

International Journal of

Medicinal Chemistry

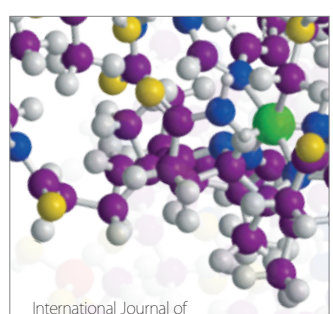

Carbohydrate Chemistry

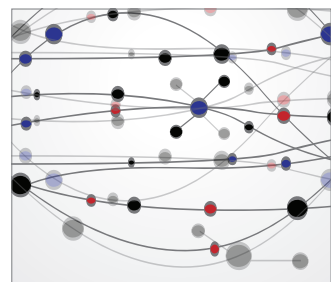

The Scientific World Journal

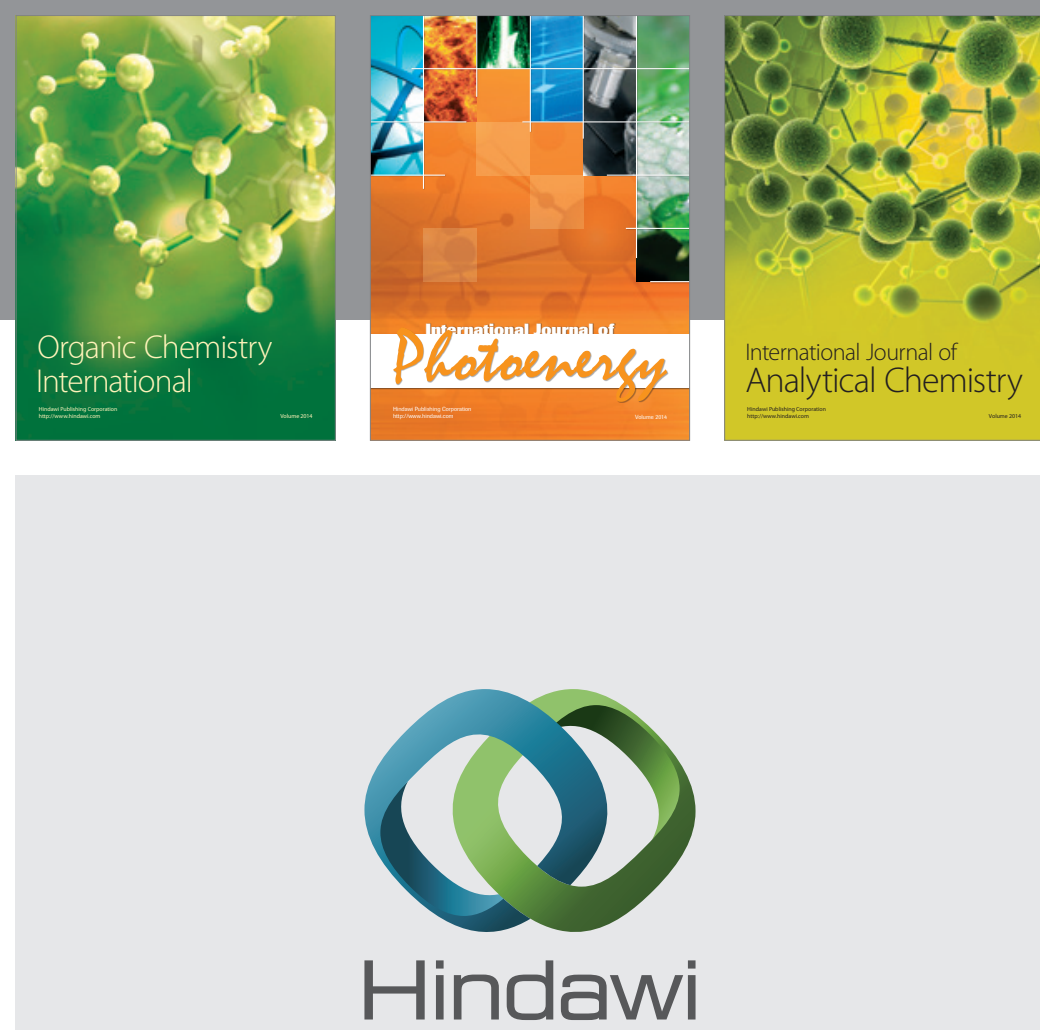

Submit your manuscripts at

http://www.hindawi.com
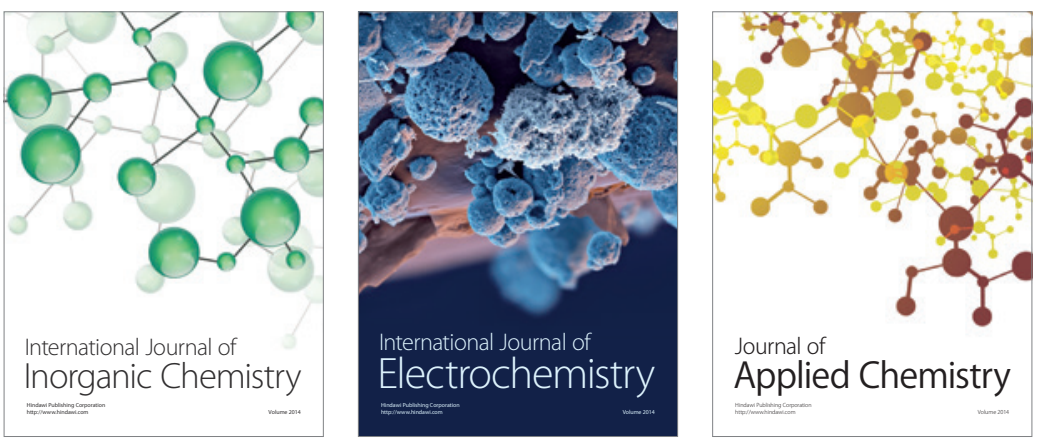

Journal of

Applied Chemistry

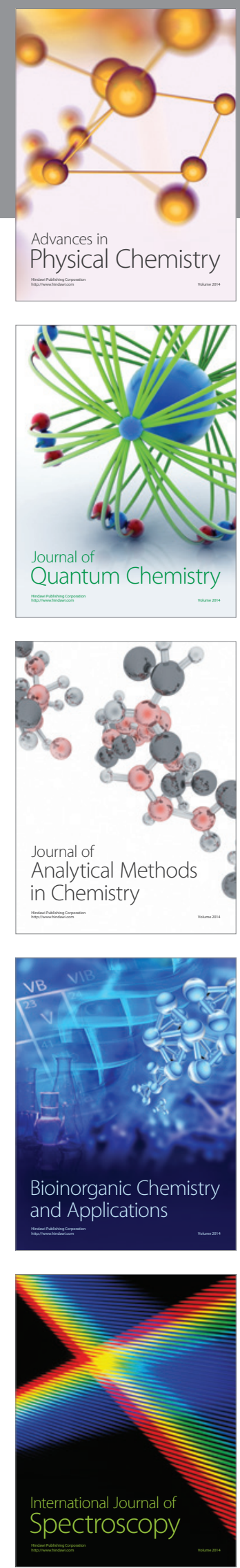